\title{
Do talento ao alto rendimento: indicadores de acesso à excelência no handebol
}

CDD. 20.ed. 796.07

796.31

\section{Resumo}

0 talento constitui uma das condições fundamentais para acender à excelência no desporto de competição e a sua identificação representa o primeiro passo de um longo processo de especialização que permite selecionar os sujeitos certos. Para conhecer as variáveis que os treinadores julgam mais influentes no sucesso do atleta de handebol (do sexo masculino), foi aplicado um questionário a 71 treinadores de handebol ("Questionário aos Técnicos de Andebol - QTA"; MASSUÇA, 2007). Neste instrumento, solicitavase aos participantes que avaliassem o grau de importância de cada fator e indicador de rendimento no sucesso em geral (Handebolista, A) e, que o fizessem igualmente para cada uma das posições de jogo que caracterizam a modalidade desportiva (Ponta, P; Lateral, L; Central, C; Pivot, Pi; Guarda-redes, GR). Os resultados permitem constatar que não existe um perfil de atleta de handebol, mas vários. Pode assim concluir-se que no jogo de handebol o sucesso pode ser experimentado por atletas com diferentes características. Em complemento, julgamos que o inventário apresentado (das qualidades necessárias ao atleta de handebol de alto rendimento) poderá servir de referência para a construção de um modelo de seleção de talentos.

UnITERMos: Modelo teórico; Multidisciplinar; Sucesso; Treinadores.

\section{Introdução}

O termo talento tem origem bíblica. Era um substantivo que denotava uma unidade monetária, amplamente usada na Grécia e em Roma (CsIKSZENTMiHalyi, Rathunde \& Whalen, 1993).

SOBRAL (1994) distingue o termo talento do termo dotado, referindo que nos dois casos, se pode ou não verificar o estado de prontidão desportiva, i.e., enquanto o talento manifesta uma elevada aptidão específica para uma forma particular de atividade (uma modalidade desportiva), o dotado demonstra capacidades de âmbito mais geral, associadas ao que se designa por disponibilidade motora ou por uma habilidade geral para realizar tarefas de caráter físico-motor. $\mathrm{O}$ termo dotado associa-se a competência geral mas o termo superdotado e talento a rendimento específico, pelo que os termos "superdotado" e talento devem ser entendidos como sinônimos.

HaHN (1988) distingue três tipos de sujeitos capazes de triunfar no campo da atividade física: 1) aqueles que apresentam um talento motor geral e são capazes de aprender com facilidade uma ampla quantidade de tarefas motoras de certa dificuldade (que seriam para outros autores os tais dotados ou superdotados); 2) aqueles que apresentam talento desportivo geral e que, para além de terem um grande talento motor geral, estão dispostos a submeter-se a um programa de treino desportivo; 3) aqueles que apresentam um talento específico desportivo e que, para além de terem talento desportivo, também têm condições para ter rendimento numa modalidade desportiva específica. Portanto, para este autor existe como que um sistema de "upgrade" que vai tornando cada tipo de sujeito uma versão melhorada da anterior.

Parece que o talento constitui uma das condições fundamentais para aceder à excelência no desporto de competição, pelo que a sua identificação representa o primeiro passo para selecionar os sujeitos certos, capazes de alcançar um nível elevado de perfeccionismo desportivo alicerçado num processo completo de especialização (Manso, Granell, Girón \& Abella, 2003). Costa e Alves (1980) referem que o objetivo da identificação de talentos é descobrir bem cedo, 
indivíduos que devido às suas capacidades motoras, somáticas e psíquicas, tenham as características necessárias para que possam vir a obter bons resultados em alta competição (permitindo, se descoberto a tempo, uma maior rentabilidade de investimento desportivo e evitando muitas frustraçôes devido a carreiras desportivas mal orientadas).

Já o processo de seleção de talentos no desporto têm como principal objetivo reconhecer quais os jovens mais aptos ou potencialmente mais capazes de atingir um elevado nível de rendimento numa determinada modalidade (Volossovitch, 2000).

Aceitar que existem sujeitos mais dispostos que outros para triunfar no desporto, foi o motivo pelo qual muitos países (e.g., Alemanha, França, Espanha, Austrália e Rússia) investiram grande quantidade de meios econômicos, humanos e materiais para descobrir na sua população mais jovem, aqueles que no futuro deveriam ocupar lugares nas seleções nacionais. Em Portugal continua a não ser dada a devida importância à problemática de identificação e seleção de talentos e por essa razão estamos consideravelmente atrasados (Marques, 1993). Neste contexto, e partindo da convicção que a evolução contínua do rendimento desportivo deve basear-se num trabalho sistemático (e a longo prazo) com os jovens talentos, é essencial que (à semelhança de outros países) se invista num modelo de identificação e seleção de talentos.

Segundo Sobral (1982), "a predição do nível de performance que a criança ou o adolescente são suscetíveis de atingir alguns anos mais tarde numa dada disciplina pode assentar numa base objetiva e constitui um dos desafios mais interessantes que hoje se apresenta aos treinadores e aos investigadores em ciências desportivas". É assim imperativo pensar o talento de forma abrangente e complexa, tornando o processo da identificação e seleção de talentos como parte integrante de um processo de preparação desportiva a longo prazo. No entanto, este processo reveste-se de grande complexidade, pelo que só a definição clara dos princípios metodológicos e critérios de seleção (de forma cientificamente sustentada), permite aumentar consideravelmente a sua eficácia (garantindo à partida uma correta orientação do jovem na escolha da modalidade).

A análise do perfil dos campeões em cada modalidade, mostra-nos tipologias (nem sempre muito convergentes) em que coabitam características comuns (essenciais) e diferenciadas. Não parece por isso haver um tipo ideal de desportistas para cada desporto, mas vários tipos ideais. Quer isto dizer que, quanto maior o número de fatores que integram a estrutura do rendimento (como ocorre no jogos desportivos coletivos), maior o número de variáveis necessárias para formular o atleta ideal, e mais difícil é (probabilísticamente) a solução do problema.

É evidente que explicar o rendimento é o desejo de muitos técnicos e investigadores do fenômeno desportivo. Contudo, a principal dificuldade na modelação da "performance" reside exatamente no seu caráter multidimensional, e no fato de se basear numa estrutura dinâmica e interativa em que todos os fatores (e indicadores) que integram a estrutura do rendimento são importantes e difíceis de hierarquizar (Brandão \& Maia, 1998; Maia, 1993). Face ao exposto, parece evidente que uma das primeiras tarefas a executar durante o processo de seleção desportiva é a definição do modelo ideal, o que normalmente pressupõe a análise das características morfológicas, funcionais, psicológicas e técnico-tácticas dos atletas de alta competição (ZATSIORSKI, 1979).

$\mathrm{O}$ referido enfatiza a pertinência dos objetivos que nos propomos atingir com o presente trabalho (e para o qual utilizamos como referência a modalidade deportiva coletiva - handebol), i.e., 1) fazer o levantamento das variáveis que os peritos julgam mais influentes no sucesso do atleta de handebol; e, 2) verificar se as variáveis de sucesso observadas diferem quando considerada a especificidade do atleta de handebol (i.e., a posição de jogo).

\section{Métodos}

No final da "Acção de Formação e Orientações Técnicas - Época 2006/2007” organizada pela Federação de Andebol de Portugal (FAP) foi aplicado o "Questionário aos Técnicos de Andebol - QTA” (MASSUÇA, 2007) a treinadores de handebol creditados pela FAP. Responderam voluntariamente ao questionário 71 treinadores de handebol (31 dos escalōes de formação, 32 do escalão senior e oito das seleções nacionais de Portugal). Num estudo prévio, Massuça e Fragoso ("in refree") observaram que a opinião dos treinadores é semelhante em 93,26\% dos casos, ou seja, das 282 variáveis estudadas apenas em 19 foram observadas diferenças significativas entre os treinadores de escalóes de formação, treinadores de equipes seniores e os selecionadores nacionais de Portugal. Face ao 
exposto, foi feita a opção metodológica de (neste estudo) não discriminar o âmbito de prática em que os treinadores/selecionadores se inseriam.

$\mathrm{O}$ instrumento aplicado (QTA) contemplava as seguintes dimensões: 1) Identificação; 2) Prática desportiva; 3) Critérios de identificação de handebolistas de (alto) rendimento desportivo; e 4) Sugestóes. Neste estudo, são analisadas apenas as respostas da terceira dimensão do questionário, na qual se solicitou aos participantes que avaliassem a importância dos fatores $\mathrm{e}$ indicadores de rendimento do atleta de handebol senior (do sexo masculino) de alto rendimento (em geral ou handebolista, A; de cada uma das posições de jogo que caracterizam a modalidade: ponta, $\mathrm{P}$; lateral, L; central, C; pivot, Pi; guarda-redes, GR).

Para classificar as variáveis utilizou-se uma escala descritiva de avaliação tipo Lickert de cinco pontos $(1=$ Pouco Importante; 2 = Nada Importante; 3 = Importante; 4 = Muito Importante; 5 = Muitíssimo Importante).

No total foram estudadas 47 variáveis para cada uma das seis situaçōes (A, P, L, C, Pi e GR; $\mathrm{n}=$ 242). Seis variáveis correspondem à importância atribuída ao: fator antropométrico (F1); fator condição física (F2); fator técnica (F3); fator tática (F4); fator psicológico (F5); fator social (F6). As restantes 41 variáveis são referentes à importância atribuida aos indicadores: estatura (F1_I01); massa corporal (F1_I02); envergadura (F1_I03); diâmetro biacromial (F1_I04); envergadura da mão (F1_I05); comprimento total do membro superior (F1_I06); comprimento do membro inferior (F1_I07); percentagem de massa gorda (F1_I08); velocidade de deslocamento (F2_I01); velocidade-agilidade (F2_I02); força inferior (e.g. impulsão vertical; F2_I03); força inferior (e.g. impulsão horizontal; F2_I04); força dorso-lombar (F2_I05); força superior (F2_I06); força média (F2_I07); força de preensão manual (F2_I08); flexibilidade ísquio-lombar (F2_I09); potência aeróbia (F2_I10); domínio dos deslocamentos defensivos (F3_I01); domínio de diferentes tipos de marcação (F3_I02); capacidade de recuperar bolas (F3_I03); capacidade de desmarcação (F3_I04); passe e recepção (F3_I05); remate (tipos; F3_I06); domínio do 1x1 (fintas; F3_I07); capacidade de criar e ocupar espaços (F4_I01); domínio dos meios táticos ofensivos e defensivos (F4_I02); colaboração defensiva (F4_I03); capacidade de variar as suas ações (F4_I04); traço de ansiedade em competição (F5_I01); motivação (F5_I02); aceitação/rejeição social (F5_I03); auto-eficácia (F5_I04); maturidade psicológica (F5_I05); impulsividade-atividade (F5_I06); tipo de habitação (F6_I01); agregado familiar (F6_I02); nível de escolaridade (F6_I03); profissão (F6_I04); ocupação dos tempos livres (F6_I05); gosto pela prática do handebol (F6_I06).

As técnicas estatísticas utilizadas foram: 1) estatística descritiva (Mediana; ver Hill \& Hill, 2002); e 2) Teste de Friedman (para detectar diferenças significativas entre os valores centrais das seis situações estudadas). Para a construção dos perfis, a importância relativa de cada um dos indicadores (\%) foi calculada com recurso a procedimentos matemáticos simples (\% Indicador $=(\mathrm{I}-1) / 4 \times[(\mathrm{F}-1) \times 0.25]$, sendo $\mathrm{I}=$ mediana da importância atribuída ao indicador; $\mathrm{F}=$ mediana da importância atribuída ao fator de rendimento). A organização e análise estatística foi efetuada com os programas informáticos: 1) Microsoft ${ }^{\circledR}$ Office Excell 2007 e 2) SPSS for Windows (Statistical Package for the Social Sciences Inc, versão 15.0, Chicago, Illinois) para $\alpha=0,05$.

\section{Resultados}

A análise das respostas ao questionário permite observar que, relativamente aos fatores de rendimento, os níveis de importância que lhes foram atribuídos pelos treinadores, diferem significativamente entre pelo menos duas posições de jogo, à excepção do fator social.

No que concerne aos indicadores de rendimento, observam-se diferenças significativas de classificação, entre as situaçôes estudadas, para todos os indicadores antropométricos e técnicos. Também se observam diferenças significativas em todos os indicadores de condição física (à excepção da flexibilidade ísqui-lombar), assim como para a generalidade dos indicadores táticos (à exceção da colaboração defensiva).
No entanto, relativamente aos indicadores psicológicos, apenas se observa diferença (significativa) relativamente ao indicador motivação. Também não existem diferenças significativas para a generalidade dos indicadores sociais, à exceção do agregado familiar, profissão e gosto pela prática do handebol.

Os resultados permitem também constatar que, segundo os treinadores inquiridos, não existe um único perfil de atleta de handebol de alto rendimento (do sexo masculino), mas sim vários. Na TABELA 1 estão sinalizadas as situações em que se observam diferenças significativas entre os valores centrais das seis situações estudadas. 
TABELA 1 - Medianas e resultados estatísticos da importância atribuída pelos treinadores aos fatores e indicadores de rendimento do atleta de handebol de alto rendimento (senior masculino), em geral (A) e para cada uma das posições de jogo (ponta, P; lateral, L; central, C; pivot, Pi; guarda-redes, GR).

NS, Não significativo; * $-p<0.05$;

${ }^{* *}-p<0.01$;

$* * *-p=0.000$.

\begin{tabular}{|c|c|c|c|c|c|c|c|c|c|}
\hline Importância atribuída ao ... & A & $\mathbf{P}$ & $\mathbf{L}$ & $\mathrm{C}$ & $\mathbf{P i}$ & GR & $\mathrm{X}^{2}(5)$ & Sig. & \\
\hline \multicolumn{10}{|c|}{ Fatores } \\
\hline Antropométrico & 4 & 3 & 5 & 4 & 5 & 5 & 204,828 & 0,000 & *** \\
\hline Condição física & 4 & 4 & 5 & 5 & 5 & 4 & 28,896 & 0,000 & *** \\
\hline Técnica & 4 & 5 & 4 & 5 & 4 & 5 & 74,669 & 0,000 & $* * *$ \\
\hline Tática & 4 & 4 & 4 & 5 & 4 & 4 & 58,732 & 0,000 & $* * *$ \\
\hline Psicológico & 4 & 4 & 4 & 4 & 4 & 5 & 36,789 & 0,000 & *** \\
\hline Social & 4 & 4 & 4 & 4 & 4 & 4 & 6,830 & 0,234 & NS \\
\hline \multicolumn{10}{|c|}{ Indicadores } \\
\hline Altura ou estatura & 4 & 3 & 4 & 4 & 4 & 4 & 201,673 & 0,000 & *** \\
\hline Peso ou massa corporal & 4 & 3 & 4 & 3 & 4 & 4 & 130,120 & 0,000 & *** \\
\hline Envergadura dos membros superiores & 4 & 3 & 4 & 4 & 4 & 5 & 155,287 & 0,000 & $* * *$ \\
\hline Diâmetro biacromial & 3 & 3 & 4 & 3 & 4 & 4 & 61,741 & 0,000 & *** \\
\hline Envergadura da mão & 4 & 4 & 4 & 4 & 4 & 4 & 32,284 & 0,000 & $* * *$ \\
\hline Comprimento total do membro superior & 4 & 4 & 4 & 4 & 4 & 4 & 52,198 & 0,000 & $* * *$ \\
\hline Comprimento do membro inferior & 4 & 4 & 4 & 4 & 4 & 4 & 68,808 & 0,000 & *** \\
\hline Percentagem de massa gorda & 4 & 4 & 4 & 4 & 4 & 4 & 17,380 & 0,004 & ** \\
\hline Velocidade de deslocamento & 4 & 5 & 4 & 5 & 4 & 4 & 94,363 & 0,000 & $* * *$ \\
\hline Velocidade-Agilidade & 4 & 5 & 4 & 5 & 4 & 5 & 100,307 & 0,000 & $* * *$ \\
\hline Força inferior (e.g., impulsão vertical) & 4 & 4 & 4 & 4 & 4 & 4 & 20,358 & 0,001 & ** \\
\hline Força inferior (e.g., inpulsão hotizontal) & 4 & 4 & 4 & 4 & 4 & 4 & 20,890 & 0,001 & ** \\
\hline Força dorso-lombar & 4 & 4 & 4 & 4 & 4 & 4 & 29,041 & 0,000 & $* * *$ \\
\hline Força superior & 4 & 4 & 4 & 4 & 4 & 4 & 45,292 & 0,000 & $* * *$ \\
\hline Força média & 4 & 4 & 4 & 4 & 4 & 4 & 21,803 & 0,001 & ** \\
\hline Força de preensão manual & 4 & 4 & 4 & 4 & 4 & 4 & 21,053 & 0,001 & ** \\
\hline Flexibilidade ísquio-lombar & 4 & 4 & 4 & 4 & 4 & 4 & 7,102 & 0,213 & NS \\
\hline Potência aeróbia & 4 & 4 & 4 & 4 & 4 & 4 & 40,861 & 0,000 & *** \\
\hline Domínio dos deslocamentos defensivos & 4 & 4 & 4 & 4 & 4 & 4 & 36,716 & 0,000 & $* * *$ \\
\hline Domínio dos diferentes tipos de marcação & 4 & 4 & 4 & 4 & 4 & 3 & 63,019 & 0,000 & $* * *$ \\
\hline Capacidade de recuperar bolas & 4 & 4 & 4 & 4 & 4 & 4 & 29,806 & 0,000 & *** \\
\hline Capacidade de desmarcação & 4 & 4 & 4 & 5 & 4 & 3 & 81,584 & 0,000 & *** \\
\hline Passe e recepção & 5 & 5 & 5 & 5 & 5 & 4 & 23,527 & 0,000 & *** \\
\hline Remate (tipos) & 4 & 5 & 5 & 5 & 5 & 3 & 91,561 & 0,000 & *** \\
\hline Domínio do 1 x 1 (fintas) & 4 & 5 & 5 & 5 & 4 & 3 & 86,314 & 0,000 & *** \\
\hline Capacidade de criar e ocupar espaços & 4 & 4 & 4 & 5 & 5 & 3 & 93,221 & 0,000 & *** \\
\hline Domínio dos meios táticos (of. e def.) & 4 & 4 & 5 & 5 & 4 & 4 & 59,660 & 0,000 & $* * *$ \\
\hline Colaboração defensiva & 5 & 4 & 4 & 5 & 4 & 4 & 7,444 & 0,190 & NS \\
\hline Capacidade de variar as suas açōes & 5 & 5 & 5 & 5 & 4 & 5 & 13,736 & 0,017 & * \\
\hline Traço de ansiedade em competição & 4 & 4 & 4 & 4 & 4 & 4 & 9,870 & 0,079 & NS \\
\hline Motivação & 5 & 5 & 5 & 5 & 5 & 5 & 14,532 & 0,013 & * \\
\hline Aceitação/rejeição social & 4 & 4 & 4 & 4 & 4 & 4 & 8,978 & 0,110 & NS \\
\hline Auto-eficácia & 4 & 4 & 4 & 4 & 4 & 4 & 2,952 & 0,707 & NS \\
\hline Maturidade psicológica & 4 & 4 & 4 & 4 & 4 & 4 & 5,050 & 0,410 & NS \\
\hline Impulsividade-atividade & 4 & 4 & 4 & 4 & 4 & 4 & 5,664 & 0,340 & NS \\
\hline Tipo de habitação & 3 & 3 & 3 & 3 & 3 & 3 & 4,433 & 0,489 & NS \\
\hline
\end{tabular}


TABELA 1 - Medianas e resultados estatísticos da importância atribuída pelos treinadores aos fatores e indicadores de rendimento do atleta de handebol de alto rendimento (senior masculino), em geral (A) e para cada uma das posições de jogo (ponta, P; lateral, L; central, C; pivot, Pi; guarda-redes, GR) (continuação).

\begin{tabular}{lrrrrrrrrr}
\hline \multicolumn{1}{c}{ Importância atribuída ao ... } & A & $\mathbf{P}$ & $\mathbf{L}$ & $\mathbf{C}$ & $\mathbf{P i}$ & $\mathbf{G R}$ & $\mathbf{X}^{2}(5)$ & \multicolumn{1}{c}{ Sig. } \\
\hline & \multicolumn{3}{c}{ Indicadores } & & & & \\
Agregado familiar & 3 & 3 & 3 & 3 & 3 & 3 & 23,600 & 0,000 & $* * *$ \\
Nível de escolaridade & 3 & 3 & 3 & 3 & 3 & 3 & 2,718 & 0,743 & NS \\
Profissão & 3 & 3 & 3 & 3 & 3 & 3 & 24,939 & 0,000 & $* * *$ \\
Ocupação dos tempos livres & 3 & 3 & 3 & 3 & 3 & 3 & 2,500 & 0,776 & NS \\
Gosto pela prática do handebol & 5 & 5 & 5 & 5 & 5 & 5 & 20,861 & 0,001 & $* *$ \\
\hline
\end{tabular}

Assim, tendo como referência a mediana da importância atribuída pelos participantes a cada um dos fatores e indicadores de rendimento (TABELA 1), construiu-se o perfil geral e os

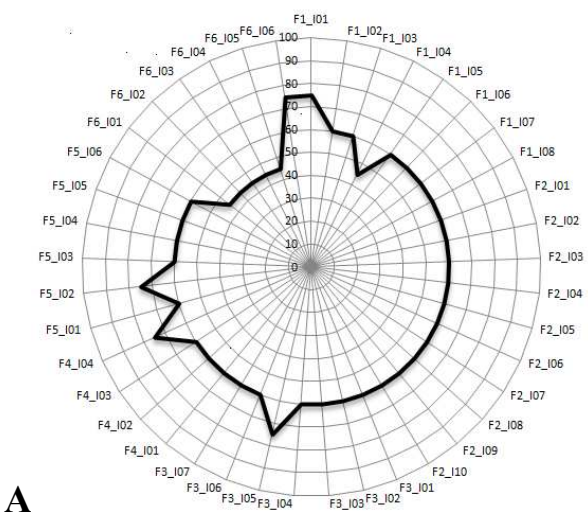

C

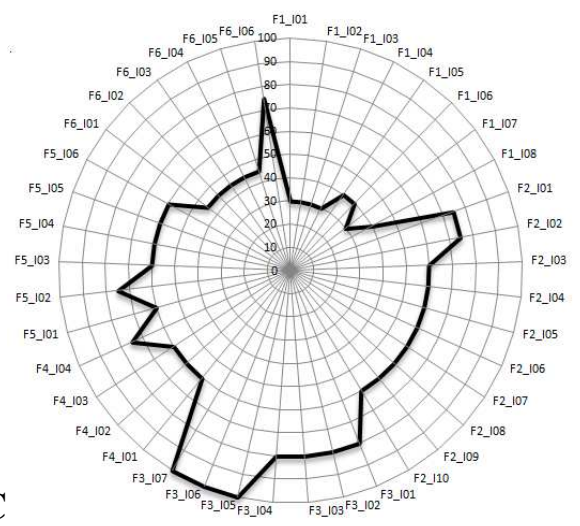

$\mathbf{E}$

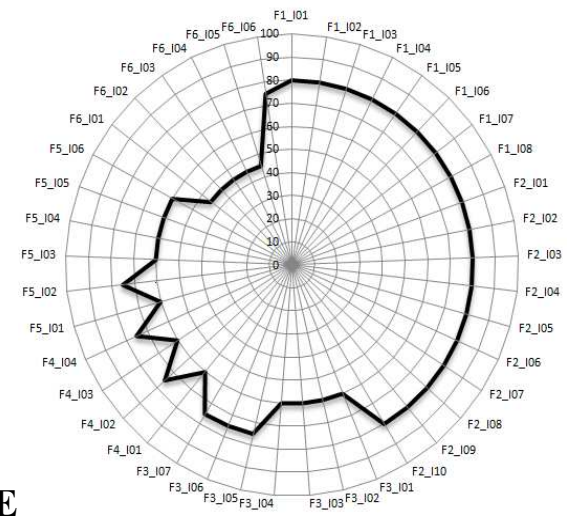

cinco perfis (um para cada posição de jogo) idealizados pelos peritos. Observando a FIGURA 1 é perceptivel que todos os perfis construídos têm configuraçôes diferentes.
B

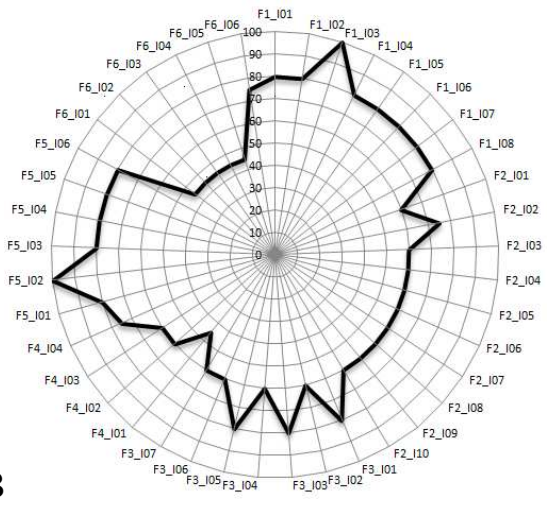

D
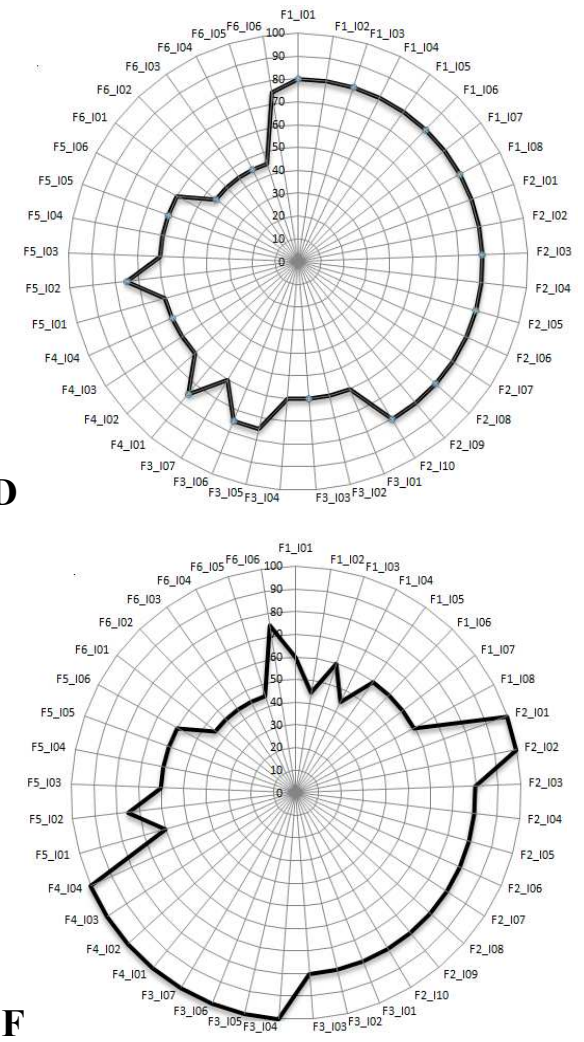

NS, Não significativo;

* $-p<0.05$;

** $-p<0.01$;

$* * *-p=0.000$.

FIGURA 1 - Perfil (em \%) do atleta de handebol de alto rendimento (em geral, A; Guarda-redes, B; Ponta, C; Pivot, $\mathrm{D}$; Lateral, E; Central, F), definido pelos treinadores de handebol portugueses $(\mathrm{n}=71)$. 


\section{Discussão}

O que é ser sujeito com talento? Um questionário feito a pais de sujeitos de reconhecido talento, inscritos no programa de Arte para Estudantes Dotados e com Talento, na Universidade de Western Illinois, revela que os pais atribuíam a habilidade artística dos filhos, ao seu talento, ao fato de estarem envolvidos nessas tarefas em casa e na escola e também ao fato de terem o pai e (ou) a mãe ligado(s) à mesma arte. Também referiram que as crianças apresentavam uma motivação intrínseca e a sua aplicação e esforço estava relacionada com o fato de quererem ser melhores. Csikszentminalyi, Rathunde e Whalen (1993) referem que os sujeitos com talento são curiosos intelectualmente (inteligentes) e ativos na recepção de informação (sensíveis). Ao mesmo tempo, expressam um forte e extraordinário desejo de se superar (realização) e estão dispostos a preservar a ordem para obter os seus objetivos (resistentes), preferindo liderar os outros para controlar melhor as suas reações (dominância). Os sujeitos com talento gostam de prender a atenção dos outros (exibição) e são menos dados a situações que questionem ou julguem o seu valor (humilhação). Em suma, este tipo de atributos estão presentes quer a nível cognitivo e motivacional, quer a nível social.

Os resultados deste estudo permitem afirmar que o atleta de handebol de alto nível de rendimento (do sexo masculino) deve ser alto e forte, destacando-se critérios antropométricos, como a estatura (embora seja um fator hereditário, menos influenciável por fatores externos, parece essencial no jogo moderno), a massa corporal, a envergadura e a envergadura da mão. Também no aspecto atlético enfatiza-se a necessidade do atleta de handebol ser rápido (possuir uma velocidade de execução muito elevada), ser potente (conseguir realizar um forte lançamento e um salto elevado) e possuir uma capacidade energética que lhe permita atrasar ao máximo os efeitos da fadiga (e a consequente diminuição da sua eficácia).

Sabendo que as condições individuais têm diferente poder explicativo do rendimento, é evidente que a ponderação da importância de cada característica individual permite estabelecer perfis, ou seja, construir o que alguns autores denominam de desportograma (GERON, 1978). Neste contexto, a FIGURA 1 permite constatar que os treinadores atribuem a máxima importância à: 1 ) envergadura e motivação do guarda-redes; 2 ) ao domínio do passe e recepção, tipos de remate e domínio do 1 x 1 do ponta; e 3) à velocidade, agilidade, capacidade de desmarcação, domínio do passe e recepção, tipos de remate, domínio do $1 \times 1$, capacidade de criar e ocupar espaços, domínio dos meios táticos ofensivos e defensivos, à colaboração defensiva e capacidade de variar as ações do central. Depreende-se assim (a partir do número de perfis inventariados) que o handebol é um jogo desportivo coletivo que possibilita a integração de sujeitos com características distintas, ou seja, é uma modalidade desportiva coletiva na qual o sucesso pode ser experimentado por atletas com características diferentes (i.e., perfis diferentes).

Mas, serão as características do um sujeito com talento atributos naturais? Muitos acreditam que alguns seres humanos são detentores à nascença de melhores "atributos" (dádivas) do que outros (e.g., sentidos apurados, melhor capacidade de memorização, entre outros). Outros porém estão convictos que a diferença de alguns não está no tamanho do pacote de atributos recebido, mas resulta da utilização e aproveitamento dado durante a vida a todos esses atributos (CSIKSZENTMIHALYI, RATHUNDE \& WhALEN, 1993), ou seja, criticam a evidência do talento como algo inato e acreditam que as grandes proezas humanas e a aquisição do conhecimento em geral se explicam melhor através da experiência, das preferências, das oportunidades de prática, do treino e da realização de tarefas difíceis (Howe, DAVIDSON \& SLOBODA, 1998). Segundo Csikszentminalyi, Rathunde e Whalen (1993), o talento é composto por características individuais (que são em parte herdadas e em parte desenvolvidas durante o crescimento pessoal), características culturais (que recorrem a sistemas de regras que definem certos desempenhos como significativos e valiosos) e características sociais (compostas por pessoas e instituições cuja tarefa é decidir se um certo desempenho será considerado valioso ou não). Por outras palavras, o talento é um rótulo de aprovação social que colocamos em determinadas características que têm um valor positivo num contexto particular. Quer isto dizer que, se alguém tem talento deverá fazer uso dessa circunstância e aprender a desempenhar os "standards" do estado de arte relativo a certo talento específico e encontrar oportunidades, após ter desenvolvido as suas capacidades, para usar o mesmo talento. Também sabemos que não é possível medir o talento inato, contudo é possível examinar a atividade realizada no passado e verificar as aprendizagens e os desempenhos a cada momento (Hyllegard, 2000), podendo projetar o futuro. Portanto, apesar da diversidade de perfis, é evidente que para integrar o alto rendimento desportivo, o atleta de handebol deve reunir uma série 
de condiçôes específicas que lhe permitam destacar-se da normalidade estatística, concedendo-lhe a possibilidade de aceder ao grupo dos melhores (BLANCO, 2004).

Mas será que nos devemos preocupar com o talento durante o processo educativo em geral e de desenvolvimento desportivo em particular? Será esta preocupação uma responsabilidade da sociedade que merece ser estudada científicamente? Existe algum benefício coletivo a partir do desenvolvimento do talento?

Parece, tal como apresentamos, que ter talento reflete ter determinadas atitudes, diferenças individuais, habilidades, ou potencialidades que em última análise fazem parte da estratégia evolutiva da espécie humana. Se fôssemos semelhantes, cresceríamos e evoluiríamos para organismos cada vez mais especializados. Neste caso estaria posta em causa a adaptação a condições variáveis e a taxa de mudança cultural estaria comprometida passando a ser assim lenta e previsível. Ao contrário a diversidade será então a base da nossa capacidade criadora.

Acreditamos pois que existem indivíduos mais dispostos que outros a triunfar no desporto em geral, e na modalidade de handebol em concreto, e sendo esta permissa verdade, então por respeito à natureza humana à sua diversidade e às estratégias seletivas e evolutivas responsáveis pela enorme criatividade adaptativa do ser humano, julgamos justificar-se o investimento na identificação e desenvolvimento de atletas talentosos. Assim, a configuração do perfil do atleta de handebol, a partir do inventário das qualidades necessárias para prática de alto nível, poderá servir de referência para a construção do modelo de identificação de talentos no handebol, onde a avaliação das capacidades do atleta, e a sua predição, podem ser comparadas e confrontadas com o modelo idealizado pelos treinadores.
Todos nós fomos abordados sobre a impossibilidade econômica de se fazer identificação e seleção de talentos. Muitas vezes medimos o custo do que gostaríamos de realizar mas não medimos o que gastamos por não termos realizado. Esta é a questão essencial. Por outro lado achamos que fazer identificação e seleção só é possível a partir de uma ampla base de recrutamento que de fato se torna pesado sobretudo quando existem grandes restrições econômicas. É evidente que um processo de identificação e seleção de talentos que faz valer este tipo de argumentos, ou seja, que obriga a um número muito elevado de praticantes só é possível em países de grandes dimensões. Como quantidade nem sempre é sinônimo de qualidade, pensamos que será economicamente mais viável identificar, conhecer e avaliar os critérios de identificação e seleção e, só depois procurar os que a eles melhor se ajustam.

A modelação do fenômeno desportivo tem servido de base ao desenvolvimento de baterias de testes simplificadas que, para além de permitirem uma seleção mais eficaz dos atletas, permitem simultaneamente rentabilizar o treino. São vários os testes e as medidas ao nosso alcance que se podem utilizar para: 1) acender ao talento desportivo; 2) identificar certas habilidades que necessitam de ser melhoradas; 3) fornecer valores de referência para estudar a efetividade dos programas de treino; e 4) definir objetivos de treino realísticos (Harman \& Pandorf, 2000). No entanto, julgamos que na ausência de um modelo teórico que garanta o enquadramento e a interpretação dos dados obtidos nas avaliações dos atletas, esses dados não passam de uma massa de números com fraco poder informativo (GréHaigne, 1992).

\section{Conclusões}

Este estudo permite constatar que, segundo os treinadores de handebol $(\mathrm{n}=71)$, não existe um perfil de atleta de handebol, mas vários. Assim, a polivalência e número de perfis inventariados, permite concluir que o handebol é um jogo desportivo coletivo que possibilita a integração de sujeitos com diferentes características, ou seja, onde o sucesso pode ser experimentado por atletas com características diferentes.

Relativamente às qualidades necessárias para a prática de handebol ao mais alto nível, julgamos que o inventário apresentado poderá servir de referência para o processo de identificação, seleção e desenvolvimento de talentos, i.e., servir de referência para a construção de um modelo de seleção de talentos. Contudo, os seis perfis que apresentamos devem agora ser avaliados segundo métodos e instrumentos credíveis, pelo que devem ser criadas condiçōes de avaliação que possam justificar e validar cientificamente os perfis desenhados. 


\section{Abstract \\ From talent to a high level of performance: key requirements to access the excellence in handball}

Talent is a key requirement to access the excellence in a competitive sport and its identification is the first step of a long process of specialization that allows the correct selection of subjects. To understand what the most influent variables to achieve success are, a questionnaire was administered to 71 handball coaches ("Questionnaire to Handball Coaches - OTA"; MASSUÇA, 2007). The coaches were asked to rate the importance of each factor and performance indicator considering the success of the general male handball player (A) and to do exactly the same for each specific playing position (wing, P; backward left/right, L; backward centre, C; pivot, Pi; goalkeeper, GR). Results showed that there is not a handball athlete profile, but several. In conclusion, this versatility and number of profiles showed that handball is a sport game that enables the integration of individuals with different characteristics and that success can be achieved by athletes with very different features. Moreover, the obtained list of qualities necessary to experience highlevel of performance can be a useful reference to the study and development of a talent selection model.

UNITERMS: Theoretical model; Multidisciplinary approach; Sucess; Coach.

\section{Referências}

BLANCO, F. Balonmano: detección, selección y rendimiento de talentos. Madrid: Editorial Gymnos, 2004.

BRANDÃO, E.; MAIA, J. A modelação da performance desportiva em basquetebol. Horizonte, Lisboa, v.14, 84, p.17-20, 1998. COSTA, J.; ALVES, J. O tempo de reacção e a detecção de talentos no andebol. Ludens, v.12, n.2, p.43-6, 1980.

CSIKSZENTMIHALYI, M.; RATHUNDE, K.; WHALEN, S. Talented teenagers: the roots of success and failure. Cambridge: Cambridge Univerity Press, 1993.

GERON, E. Psychological assessment of sport giftedness. In: SIMRI, U. (Ed.). Proceedings of the international symposium. Local: Ed., 1978.

GRÉHAIGNE, J.F. L' organisation du jeu en football. Paris: Editions Actio, 1992.

HAHN, E. Entrenamiento con nińos. Barcelona: Martínez Roca, 1988.

HARMAN, E.; PANDORF, C. Principles of test selection and administration. In: BAECHE, T.; EARLE, R. Essentials of strength training and conditioning. 2nd ed. Champaign: Human Kinetics, 2000. p.275-307.

HILL, M.; HILL, A. Investigação por questionário. 2. ed. Lisboa: Edições Sílabo, 2002.

HOWE, M.J.A.; DAVIDSON, J.W.; SLOBODA, J.A. Innate talents: reality or myth? Behavioral and Brain Sciences, Cambridge, v.21, p.399-442, 1998.

HYLLEGARD, R. Parental attribution of artistic ability in talented children. Perceptual Motor Skills, Missoula, v.91, n.3, pt.2, p.1134-44, 2000.

MAIA, J. Abordagem antropobiológica da selecção em desporto: estudo multivariado de indicadores bio-sociais da selecção em andebolistas dos dois sexos dos 13 aos 16 anos de idade. 1993. Tese (Doutorado) - Faculdade de Ciências do Desporto e Educação Física, Universidade do Porto, Porto, 1993.

MANSO, J.; GRANELL, J.; GIRÓN, P.; ABELLA, C. El talento deportivo: formación de élites deportivas. Madrid: Gymnos, 2003. MARQUES, A. Bases para a estruturação de um modelo de detecção e selecção de talentos desportivos em Portugal. Espaço, Porto, v.1, n.1, p.47-58, 1993.

MASSUÇA, L. Subsídios para a construção do modelo de rendimento do andebolista: perfil morfo-funcional do andebolista sénior masculino. 2007. Tese (Mestrado) - Faculdade de Motricidade Humana, Universidade Técnica de Lisboa, Cruz Quebrada, 2007.

SOBRAL, F. Algumas considerações sobre a detecção dos talentos desportivos. Ludens, v.6, n.3, p.8-13, 1982.

. Desporto infanto-juvenil: prontidão e o talento. Lisboa: Livros Horizonte, 1994.

VOLOSSOVITCH, A. Aspectos metodológicos da selecção de talentos desportivos. Treino Desportivo, Lisboa, p.2-7, 2000. Especial 3.

ZATSIORSKI, V. Metrología deportiva: cultura física y deportes. 2. ed. Moscú: Cultura Física y Deportes, 1979. 
ENDEREÇO

Luís Massuça

Faculdade de Motricidade Humana Universidade Técnica de Lisboa

Estrada da Costa

1495-688 - Cruz Quebrada - Dafundo - PORTUGAL e-mail: luis.massuca@gmail.com
Recebido para publicação: 02/12/2009

1a. Revisão: 15/03/2010

2a. Revisão: 21/05/2010

Aceito: 25/05/2010 